\section{Routine Whirlpool Cultures: The Liabilities of Performance and Discontinuation}

\section{To the Editor:}

I have heard Dr. Harry Nottebart speak on several occasions on the legal aspects of infection control as well as read his segment on the medical-legal policies in the book Handbook of Hospital Acquired Infections. It has been helpful in my work as an Infection Control Coordinator. Therefore, I would like his advice on the following situation.

My hospital has continued to culture whirlpools routinely in the Physical Therapy Department even though the CDC recommended against routine environmental cultures. The hospital recently had a change in department heads of Physical Therapy, so I, again, suggested discontinuing these routine cultures, giving the following reasons:

1. The CDC's latest released guidelines recommended against routine environmental cultures with the exception of two areas, hemodialysis and central sterile supply.

2. The hospital had never experienced any problems with patient infections related to whirlpool treatment.

3. Whenever there was a positive culture, it was difficult to interpret its significance.

The Physical Therapy Department Head was in agreement but met with resistance from the hospital administration as well as the Risk Manager. Their objection of suddenly discontinuing cultures of whirlpools was based upon the fear of the hospital's liability. I would like to know if this objection is justified, as well as any other comments or recommendations. Thank you for your assistance.

Dotti Smith, RN, BS, CIC Infection Control Coordinator Fallston General Hospital Fallston, Maryland
Dr. Nottebart responds to Ms. Smith's letter:

\section{Ms. Smith:}

Thank you for your letter and kind comments. Your letter raises an important issue which frequently appears in various guises these days and is compounded by the fear of lawsuits and possible liability. What does one do about a procedure that no longer has any logical justification, or about which one now has data showing that that procedure is no longer necessary, but there is fear of stopping it?

Inertia can be a major problem to overcome.

From your letter it sounds as if you already have clearly, succinctly, and logically presented the reasons for discontinuing routine cultures of the whirlpools in Physical Therapy. For the hospital to be liable after discontinuing routine whirlpool cultures, the plaintiff would have to show that such discontinuance was the proximal cause of the alleged injury. That might be possible, but only if your cultures were used to indicate when certain cleaning procedures were necessary. Then the failure to culture would prevent the hospital from knowing when to use those cleaning procedures, and a subsequent whirlpool-acquired infection might be due to the failure to cultures. All of that seems highly unlikely and even far-fetched.

One, of course, should always emphasize the fact that the proposal is to discontinue routine culturing of the whirlpools. When there is any reason to culture the whirlpools based on surveillance, chart review, laboratory results, or whatever method you use for identification of nosocomial infections, then one will culture the whirlpools-but only on an as-needed basis, not routinely.

One should also point out that you have the data from your own hospital showing that there are no documented patient infections related to the whirlpools and that any positive cultures from the whirlpools could not be related to patient infections.

One practical approach might be to change the frequency of routine culturing to something more manageable, like annually, or perhaps every February 29.

One approach that would work in some hospitals is to use the committee structure that is in place. One would start with the Chairman of the Infection Control Committee. Present the data and show there is no need for routine whirlpool cultures. Once you convince the Chairman, you should then individually approach any infectious disease physicians on the committee, make sure they concur with your proposal, and enlist their aid in talking with other key members of the Infection Control Committee. After you have completed this ground work and individually convinced the key members, you can then put it on the agenda for the next Infection Control Committee meeting. If you have the concurrence of the majority of the Infection Control Committee you can then get the Committee to make the proposal an official recommendation and part of the Committee's minutes. In many hospitals this would then go to the Executive Committee of the Professional Staff and from there to the Board of Directors. If this recommendation is passed by all of these bodies, then perhaps the hospital administration and risk management people will consider the proposal carefully.

In the meantime, of course, one would compile the data on what it costs in terms of personnel (both to obtain specimens and to process them) and supplies to culture the whirlpools and project that cost at the current frequency to cost per year. This may be a large enough amount so that at least the proposal to eliminate routine culturing of the whirlpools is seriously considered.

One might also compile a table showing results of previous cultures and the negative correlation that exists between both the positive and negative 


\section{This Publication is available in Microform.}

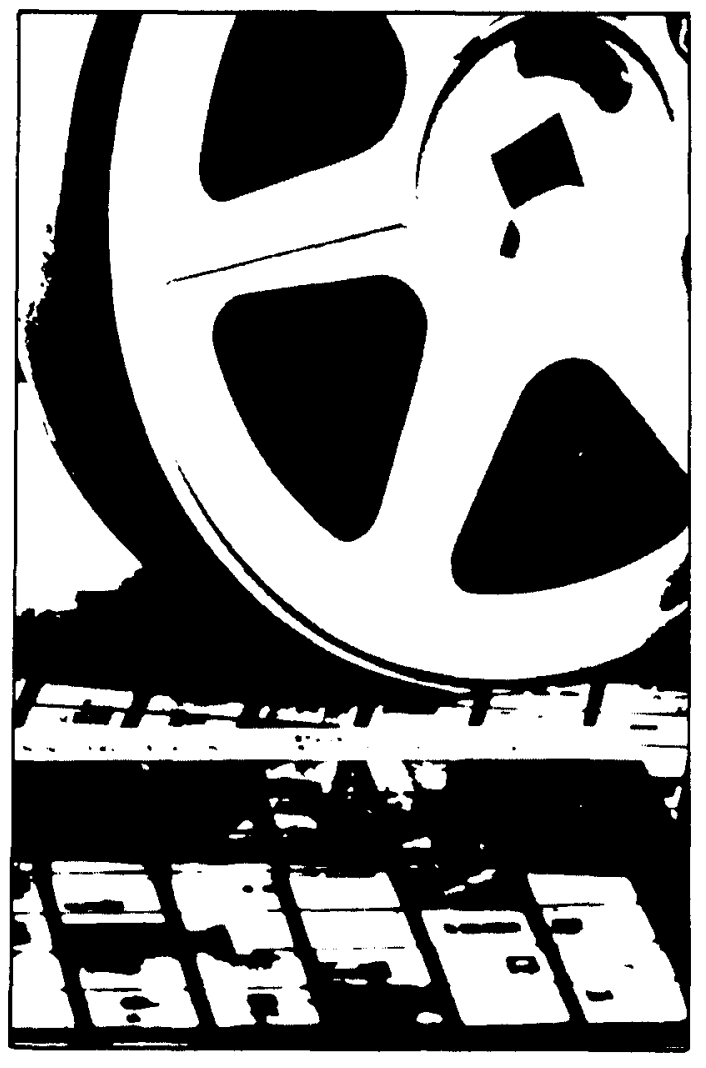

\section{University Microfilms International}

Please send additional information

for

Name

(name of publication)

Institution

Street

City

State

Zip

300 North Zeeb Road

Dept. P.R.

Ann Arbor, Mi. 48106 cultures. In this way you are showing not only how expensive this is but that it produces data which is of no use.

Another approach, but a very dangerous one in my opinion, is to take the opposite tack. If culturing whirlpools routinely is a good thing to do perhaps it should be done more frequently. Daily? Hourly? Since the cultures you mention are most likely the usual aerobic cultures, are you possibly missing something? Perhaps you should do these routine cultures for anaerobes, fungi, mycobacteria (wait until one of the cultures is positive for $M$. gordonae) and even viruses!

Why limit yourselves to the whirlpool baths? If one wants to routinely culture things, why not culture the buckets used in washing the floors and walls, the food in the Dietary department, the IVs and medications in the Pharmacy, the skin, etc of all employees, patients and visitors, air samples from all parts of the hospital, etc, etc ad infinitum. There does not have to be any end. One can generate mounds, even tons, of useless but expensive data worth absolutely nothing or worse. Time and supplies will have been taken from needed and useful items to feed this insatiable bureaucratic nightmare.

As clear as it is to you and me and thousands of others, you may not be able to get this changed. Once something like this gets started, it is very difficult to stop. Probably the best approach is to point out that the data in your own hospital shows there is no correlation between the results of routine whirlpool cultures (either positive or negative) and nosocomial infections and what this useless data costs.

Do not be disappointed if logic and rationality do not carry the day at this time. Continue to compile the data from routine cultures with patient correlation (and presumably there will be no correlation) for another 6 months or so and then present the data again to the Infection Control Committee. If the data continue to support the discontinuance of routine whirlpool cultures, then eventually this will become as obvious to everyone else as it is to you now. Changes often have to progress like a coral reef-a little at a time.

Harry C. Nottebart, Jr., JD, MD Richmond, Virginia 